\title{
Online anaphylaxis training for schools is effective and feasible
}

\author{
Anthony J Levinson ${ }^{1 *}$, Lisa Colizza ${ }^{1}$, Michael Hauptman², Laurie Harada ${ }^{3}$, Susan Waserman ${ }^{4}$, Sarah Garside $^{1}$ \\ From Canadian Society of Allergy and Clinical Immunology Annual Scientific Meeting 2010 \\ Victoria, Canada. 3-6 November 2010
}

\section{Background}

In this study, we tested the effectiveness of an online training program about the recognition, management, and prevention of anaphylaxis in the school setting.

\section{Materials and methods}

The study was conducted in Alberta between November 2009 and January 2010. 105 elementary and secondary school teachers, school administrators, educational assistants, custodial staff, and volunteers participated in the study.

The training program was approximately 1 -hour in duration and covered knowledge of anaphylaxis, skills of how to use an auto-injector, and prevention strategies based on the latest expert consensus guidelines. [1] The multimedia program had a high degree of interactivity and used evidence-based instructional design. [2] Using a pretest-intervention-posttest design, knowledge and skills were assessed with 11 graded items on the pretest and 9 graded items on the posttest that were validated through expert consensus and pilot testing. Participant confidence was also measured. Data were analyzed using repeated measures ANOVA.

\section{Results}

Of the 105 participants that enrolled in the program, complete data was available for 74 participants. There was a significant improvement in knowledge $F(1,66)$ $=27.7, \mathrm{p}<0.001$ with the mean pretest score of $51.1 \%$; and mean posttest score of $78.2 \%$; giving a large effect size for the intervention of 1.7. Participant confidence to use an auto-injector in an emergency rose dramatically following the program, and learners were very satisfied with the program.

\section{Conclusions}

Our Internet-based training program on anaphylaxis is a highly effective training program for school personnel. Further research on optimal implementation strategies and longitudinal follow-up of knowledge, skills and attitudes is required.

\section{Acknowledgements}

This research was supported by AllerGen NCE Inc. The program was developed by Anaphylaxis Canada, the Canadian Society of Allergy and Clinical Immunology, and Leap Learning Technologies Inc., with additional support from the Government of Alberta and the Division of e-Learning Innovation at McMaster University.

\section{Author details}

'Division of e-Learning Innovation, McMaster University, Hamilton, Ontario, Canada, L8N 3Z5. ²Evergreen Catholic School Division, Alberta Ed, Spruce Grove, Alberta, Canada, T7X 3B4. ${ }^{3}$ Anaphylaxis Canada, Toronto, Ontario, Canada, M2J 5B4. ${ }^{4}$ Division of Clinical Immunology and Allergy, Department of Medicine, McMaster University, Hamilton, Ontario, Canada, L8N $3 Z 5$.

Published: 4 November 2010

\section{References}

1. Canadian Society of Allergy and Clinical Immunology: Anaphylaxis in Schools \& Other Settings. Ottawa: CSACl, 2 nd 2009.

2. Cook DA, Levinson AJ, Garside S, Dupras DM, Erwin PJ, Montori VM: Internet-Based Learning in the Health Professions: A Meta-analysis. JAMA 2008, 300:1181-1196.

\section{doi:10.1186/1710-1492-6-S2-P5}

Cite this article as: Levinson et al:: Online anaphylaxis training for schools is effective and feasible. Allergy, Asthma \& Clinical Immunology 2010 6(Suppl 2):P5.

\footnotetext{
* Correspondence: levinsa@mcmaster.ca

'Division of e-Learning Innovation, McMaster University, Hamilton, Ontario,

Canada, L8N $3 Z 5$

Full list of author information is available at the end of the article
} 